\title{
Expanding the Gene Pool
}

\author{
BERNARD P. RICCA \\ St. John Fisher College (USA)
}

Figure 1 is taken from Yaneer Bar-Yam's 1997 book, Dynamics of Complex Systems. What is immediately obvious to many readers of Complicity is that education does NOT appear in this figure. ${ }^{1}$ Furthermore, relatively little work in complexity since 1997 has focused on education. We might ask ourselves, when there is so much interdisciplinary work done from a complexity perspective, why so little of that work examines education. Many hypotheses may come to mind, including these:

- Because almost all researchers have been through 16 or more years of school, they may believe school to be well understood.

- Because almost all researchers have been through 16 or more years of school, they may be too weary of education to want to engage with it any further.

- Researchers may believe school to be simple (although Bar-Yam's figure dissuades us somewhat from that thought).

- Researchers may implicitly believe that school is too complex to attempt to understand. It is not the purpose of either this editorial or this issue to settle the question of which of these hypotheses, if any, is supported by reality. Instead, the purposes of this issue are two-fold. One purpose is to bring some complexity researchers who are normally outside of the Complicity milieu, and mostly who are usually outside of education, to focus their talents on questions in

\footnotetext{
${ }^{1}$ Bar-Yam does, in other works, consider education and complexity. This figure is chosen as a convenient example of the field of complexity, and its use here is not intended to be a comment on any individual's work.
} 
(a)

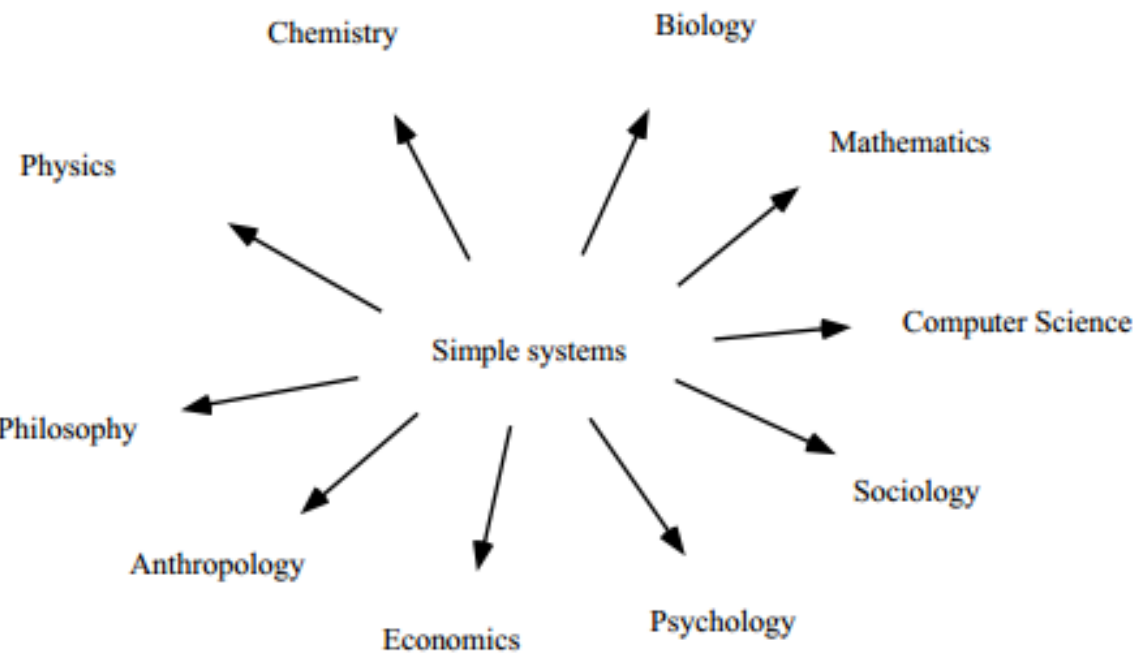

(b)

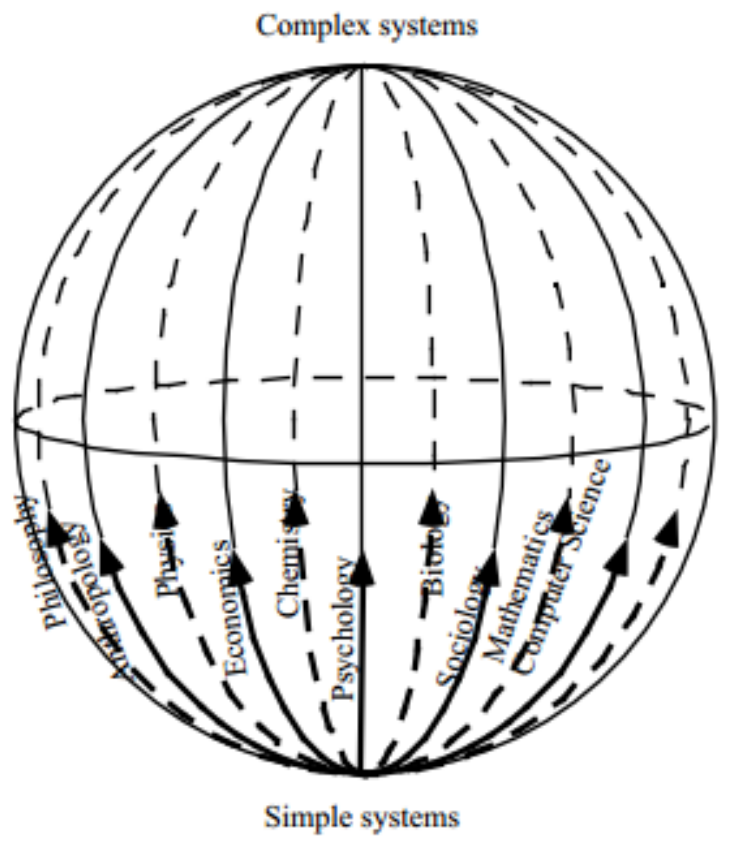

Figure 1. Taken from Y. Bar-Yam, Dynamics of Complex Systems, Westview Press, 1997, p.3. Used with permission.

education, and perhaps thereby to provide new insights into the relationship of complexity and education. The second purpose is, through this process, to further open up some avenues of inquiry within complexity and education.

\section{High Country Adventures}


Kauffman $(1993,1995)$ examined evolution in ways that can apply to situations other than biological evolution. In his way of thinking, species evolved by climbing fitness landscapes. While bringing some rigor to concepts such as self-organization, two of his insights are particularly useful in placing complexity in relation to education: the idea of fitness landscapes, and an understanding of evolutionarily stable strategies.

Kauffman noted that, for a species that is relatively new to an environment, it is possible to make relatively large gains in fitness through minor genetic changes. This occurs because (a) the immigrant species is likely not well adapted to its new environment and (b) the fitness landscape is very rugged from the perspective of the immigrant species; that is, the landscape is relatively uncorrelated to the genetic structure of the species. However, as a species' time in the environment increases, its fitness increases, and the landscape seems to become less rugged until, for a very "ancient" species, the landscape consists of a single relatively gently sloping "hill" to climb. In fact, the landscape becomes so gently sloping that any fitness gained by moving up the hill (due to changes in genetics) is offset by the general drift that entropy would apparently require, and the species ceases to change. The change to a different, and perhaps taller, "hill" in a highly correlated environment requires a great change in underlying genetics.

Taking care to avoid some of the potential pitfalls of methodological borrowing (Gough, 2012), the concept of a fitness landscape can be applied to ideas in education. In doing so, it makes sense that initial forays into an intellectual field can produce large gains in understanding, while simultaneously finding methodical progress to be difficult. First, an immigrant idea, followed by a relatively short period of careful study, can act like the first few mutations of an immigrant species, producing a relatively large gain. (This is very much the thinking behind inviting "external" voices to contribute to Complicity; these authors bring new ideas and some initial careful study.) However, method requires both a fitness of the ideas to the field and a correlation between nearby variants of the field, so that the initial large gains may not be very methodical. Of course, as method gains more in rigor - as the ideas "fit" the field better - the field must be careful to avoid a state of rigor mortis, as Bill Doll has pointed out on many occasions: As the method comes to better fit the field, it finds the field to be only a gentle slope; it is simultaneously unable to get off of that hill, and hence is unable to make much further progress.

This metaphor about the evolution of ideas has, I believe, many things to say to those who work in complexity and education. Two, however, are of particular interest here. The first is that, absent new "species" of thought, we may find ourselves at a point where the relationship between complexity and education grows stagnant. How much time it takes to become stagnant, and where we - either as a field or as individuals - are on the fitness landscape, are both unknown. Second, the introduction of new species can lead to ideas that might be quite uncorrelated with our previous ideas. Thomas Kuhn (2012) spoke of paradigms, and how "normal" research operated within a paradigm. He also noted that new experimental data can challenge the paradigm, changing the intellectual landscape and opening the way for new ideas by reducing the fitness of the old ideas (and making the landscape seem more rugged). Sometimes, however, evolution is prompted not by changes in the landscape, but by changes in the organism in radical ways. While most radical genetic changes or introduction of new genes cause the extinction of a species, there are some new genes that may actually lead to 
higher fitness. It is hoped - for reasons given below - that the introduction of the new (at least to this milieu) species of ideas in this issue can lead to inter-species "breeding" with little concern about extinction.

In addition to fitness landscapes, Kauffman (1993) examined the conditions under which a species might be evolutionarily stable. An evolutionarily stable species (ESS) is one that does not allow a mutation to propagate through the species; often such species are also stable against other competitors as well. Again, backwards echoes (pre-echoes?) of this idea can be seen in Kuhn's notion of paradigms, which are entities that tend to admit only ideas that arise from the same paradigm. Kauffman, however, would have us look at the notion of competing ideas in a different way: Instead of the existing paradigm determining the fate of a non-paradigmatic idea, both of the competing ideas - the old and the new - must grapple for resources in an environment that a priori privileges neither. Further, while the environment can be changed by either or both species, neither species determines the environment by itself, not even the two species together necessarily determine the environment. It is perhaps a Kauffman-esque approach to competing ideas that makes more sense in today's world - where innovation and change rather than replication in a paradigm might be the rule - than does Kuhn's. Clearly, however, Kuhn idea has not gone away: Lortie (1975), echoing Kuhn, reminds us that teachers teach as they've been taught, and that sentiment is repeated frequently. (Indeed, it sometimes seems that education has changed not at all over more than a generation.) However, it is certainly the possibility of Kauffman-esque evolution that prompted the original idea to approach "external" authors for this issue.

\section{Metaphor}

However, not all new species provide genes that can be helpful. In an academic setting, new species of ideas have an impact only if they share sufficient features with the existing gene pool, so that they may interact, while maintaining enough difference so that there is something new; a "difference that makes a difference" (Bateson, 1972) or a balance of diversity and redundancy (Davis \& Sumara, 2006). It is likely that one requirement of the difference that makes a difference is that the new genes and the old must share a root metaphor.

Thelen (1999) spoke of looking inside the black box of the mental life. While many aspects of education may appear to be open for inspection, it is generally only the structure, and not the organization, that is immediately apparent (and often, the structure isn't even apparent). The relationships that actually create a difference, and the components that may self-organize, may not be so readily apparent. Hence, almost all aspects of education involve some form of a black box. Thelen proposed the model of Figure 2, describing it this way:

The only way to get an entree into the fabled black box is through asking how the processes of mental life are like something else whose processes are somewhat more transparent. So before we begin any foray into data collection, formal models, or verbal theory we adopt what has been called a 'root metaphor.'...In this scheme, the meta-phor/meta-theory determine both the data to be collected and the models generated. There are two pathways that can be followed in doing this. One is from Metaphor - to data - and then to the model.... But even if we never approached the formal models, I defend this approach as long as the metaphor organizes existing data, generates testable and falsifiable hypotheses, makes contact with other levels of organization 
and generally helps us understand how the system works. When the models are developed, they will grow organically from a long dialogue between the metaphor and the data....[Successful work] began with a phenomena....and quite thoroughly described that phenomena before they fit the data with an appropriate model....The model generated predictions about the system that were tested experimentally. Presumably if the experiments had not confirmed the model predictions, they would have changed the model, not looked for a different phenomenon ( $p$. 152-3).

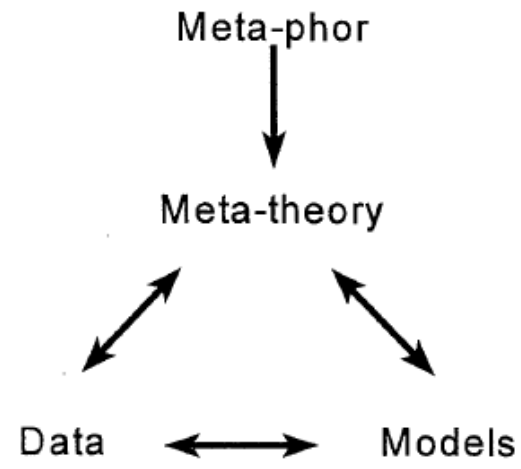

Figure 2. Taken from E. Thelen. The Dynamics of Motor Development, p.153. In Non-linear Developmental Processes. Edited by G. Savelsbergh, H. van der Maas and P. van Geert, Elsevier, 1999. Used with Permission.

To a large extent, the authors of the pieces in this issue all share a root metaphor, and thus these contributions, even from those outside of education, will likely provide useful new ideas to those in education.

\section{Expanding the Gene Pool}

The aim of biological theorizing is not, as it is in physical science, the identification of natural laws, but the sharpening of tools for interacting with the biosphere.

(Rosenberg, p. 254)

If one were to replace "biology" with "education" in Rosenberg's statement, then most readers of Complicity would likely agree with the result. This special issue, drawing heavily on authors who are outside of the usual milieu of Complicity, is an attempt to help readers work with tools that may be unfamiliar to them. The goal of the issue is not to replace the tools that are already common to the Complicity readers, or even to compete with those ideas, but rather to use the (possibly) unfamiliar as a way to refine and revise our use of the familiar, and to promote further insight into the "edusphere". In this way, we move away from Kauffman, who seems to search for universal laws, and (hopefully!) avoid the inappropriate privileging of the source of borrowed material that Gough (2012) warns against.

The use of "outside" voices to sharpen tools not a new idea. The use of outside consultants to spark a change is common in organizations. As summer (where I live) draws to a close, and we come closer to a new school year, the standard "professional development day" 
looms. Many of us will have had the experience of attending such a professional development led by an "expert" from outside the institution. Additionally, during the last year, I was involved in meetings with teachers and administrators in the rural areas surrounding my college. One of the themes that kept arising was that rural schools are limited not by their personnel, but by their access to new ideas; in the words of one Superintendent, "our gene pool needs to be expanded". This issue hopes to do the same for the readers of Complicity.

\section{Overviews}

This issue of Complicity, then, brings together a group of "external" voices to the conversations about education and complexity. Authors were solicited, and requested to write about education, broadly conceived, from their own perspective and many were quite excited to do so. While the original thought when proposing the issue was to bring some "new genes" into the Complicity gene pool, the resulting pieces do much more than that.

The pieces here can, and should, be read in many ways. One way is the usual analytical approach in which we are all trained: What is the content, argument, etc.? However, there is a second approach to reading these pieces as a collection: To the best of my knowledge, none of the authors were in communication about their pieces with the other authors, although some of the authors were familiar with each other and each other's work before this issue. Despite the lack of overt coordination, there is substantial overlap in thinking between many of the pieces, and these overlaps can provide insight into our shared metaphors. Third - and this is in the spirit of the second reading - by approaching these with a stance of "How does this article help me sharpen my own work?" I think that the reader will find immense wealth here.

The six articles included in this issue come from a wide range of interests. While some of the authors may be familiar to Complicity readers, none of the authors have previously published in Complicity, and several would consider their intellectual home to be outside of education. Some of the pieces are quantitative, and while some come from a flavor of complexity that is not usually associated with this journal, such as nonlinear dynamical systems, there is little doubt that these pieces all come from a similar root metaphor.

These pieces fall naturally into two groups of three and a few words of introduction are in order for each of these pieces:

First, there is a group that examines the field of education and society, and how a complexity stance might benefit education; this group includes the pieces by Doug Keil, Paul van Geert and Henderien Steenbeek, and David Byrne. Doug Kiel writes about the difficulties, if not the impossibilities, of humans keeping up with the rapid changes of modern society. The rapid pace of these changes, compared to the relatively slow changes in how we prepare for these changes, creates a "complexity gap" with some important consequences for both education and society, and Kiel examines this complexity gap and what society might do to grapple with it. Paul van Geert \& Henderien Steenbeek, also address a complexity gap of sorts: it seems that we must, in order to deal with the world, reduce its complexity to something more manageable. How to bridge the gap between the complexity that we can manage, and the complexity that is, holds a number of implications for education. They too, examine this gap and what might be done to grapple with it. One approach that may contribute to bridging both of these complexity gaps can be found in David Byrne's contribution. Drawing from his own 
experience teaching and researching complexity, Byrne explicates a pedagogy OF complexity. In many ways, his approach fits very well with the examinations of the other two pieces.

The second group reports on empirical work; this group includes the pieces by Dimitrios Stamovlasis, Aini-Krisitina Jäppinen, and Porfirio Guevara, and these empirical papers are arranged in order of increasing scale, from learning in individuals up through policy at a national level. Dimitri Stamovlasis examines science learning in a novel manner. Instead of focusing on content knowledge and/or (so-called) learning progressions, he considers how student learning in science is mediated by two factors generally considered external to the content: reasoning, and field dependence/independence. Each of these factors plays a role in science learning, and their combination provides an additional insight into that learning. (It is interesting to note how the focus on content knowledge and/or learning progressions usually privileges the disciplinary canon over the learner. Stamovlasis instead, privileges the learner in the analysis.) Aini-Krisitina Jäppinen examines educational leadership, focusing on how those involved in leadership make sense of their complex educational situations - echoes of Van Geert \& Steenbeek - but also on how that sense-making is not located solely in the educational leader, but in the educational system. Porfirio Guevara Chaves adopts a more systems-level approach to understanding phenomena, such as school dropouts, that are often examined on an individual basis.

While readers of Complicity will likely choose articles to read based on their own needs, I would encourage readers to explore all six of these articles.

In addition to the articles here, this issue includes a vignette co-authored by a recently deceased colleague, and a review of the Santa Fe Institute's Introduction to Complexity MOOC.

\section{A Remembrance}

It is with much sadness that I must report the untimely passing of Sherrie Reynolds. One of Sherrie's academic pieces, which she worked on with her graduate student, Julie Vu, was unfinished at the time of her death. That unfinished piece, refined by her friends and Julie, is included in this issue. Sherrie was my graduate advisor in Education and the person who first showed me that complexity and education were closely linked. She was known to many in the education community and many were moved by her ability to be fierce without being rancorous, and to be gentle without being weak. The world is a better place for having had her in it, and we miss her.

\section{References}

Bar-Yan, Y. (1997). Dynamics of complex systems. Boulder, CO: Westview Press.

Bateson, G. (1972). Steps to an ecology of mind. Chicago, IL: University of Chicago Press.

Davis, B., \& Sumara, D. (2006). Complexity and education: Inquires into learning, teaching and research. New York, NY: Routledge.

Gough, N. (2012). Complexity, complexity reduction, and 'methodological borrowing' in educational inquiry. Complicity: An International Journal of Complexity and Education, 9(1), 41-56.

Kauffman, S. (1993). The origins of order: Self-organization and selection in evolution. New York, NY: Oxford University Press.

Kauffman, S. (1995). At home in the universe: The search for the laws of self-organization and complexity. New York, NY: Oxford University Press. 
Kuhn, T. (2012). The structure of scientific revolutions ( $4^{\text {th }}$ ed.). Chicago, IL: University of Chicago Press.

Lortie, D. (1975). Schoolteacher: A sociological study. Chicago, IL: University of Chicago Press.

Rosenberg, A. (1979). Reductionism to instrumentalism? In M. Ruse, (Ed.) What the philosophy of biology is: Essays dedicated to David Hull (pp. 245-262).Dordrecht, Germany: Kluwer.

Thelen, E. (1999). The dynamics of motor development: Commentary on Wimmers and Vereijken. In G. Savelsbergh, H. van der Maas, \& P. van Geert (Eds.), Non-linear developmental processes (p. 151-155). Rotterdam: Elsevier.

\section{About the Author}

Barney Ricca is the Director of the Graduate Math, Science and Technology Education program at St. John Fisher College in Rochester, NY. He is a physicist by training, who now works in education by being an Associate Professor in a mathematics department, as is appropriate for someone with interdisciplinary tastes in research and teaching. His main research interests are in complexity, research methodology, and teacher education, and he teaches a wide variety of courses in education, statistics, and network theory. He is the Editor-in-Chief of Complicity. His family recently acquired an 8 week old, black, Labrador Retriever and all of the fun and work that goes with such an acquisition. Email: Complicity.Journal@gmail.com

(c) Copyright 2014. The author, Bernard P. Ricca, assigns to the University of Alberta and other educational and non-profit institutions a nonexclusive license to use this document for personal use and in courses of instruction provided that the article is used in full and this copyright statement is reproduced. The authors also grant a non-exclusive license to the University of Alberta to publish this document in full on the World Wide Web, and for the document to be published on mirrors on the World Wide Web. Any other usage is prohibited without the express permission of the authors. 